\title{
Aerosols and spacers for acute asthma in children. Evolution and time to change the routine
}

\author{
Jose Dirceu Ribeiro *
}

Several studies have shown that valved (metal or plastic) spacers and, even homemade spacers (made out of bottles and plastic cups), are equivalent to or more advantageous than nebulizers for the delivery of medication in acute asthma attacks. ${ }^{1-4}$

These studies have resulted in the publication of extensive reviews and meta-analyses about the delivery of drugs through different devices, with or without spacers. ${ }^{5-8}$

A recent review 6 analyzed the results of 394 randomized and controlled trials selected from a total of 2,100 studies, published in MEDLINE from 1972 to 2000, comparing the administration of bronchodilators, inhaled corticosteroids and anticholinergic agents through pressurized metered-dose inhalers (PMDI), PMDI with spacers, nebulizers, and dry-powder inhalers. The following studies were selected by the authors: 131 studies comparing different types of spacers, 45 comparing PMDI with dry-powder inhalers, 32 comparing nebulizers with PDMI using valved spacers; 14 comparing dry-powder inhalers with PMDI with spacers, three comparing dry-powder inhalers with nebulizers, five comparing PMDI with nebulizers and seven comparing continuous inhalation with intermittent inhalation.

The conclusion is that, if properly used, all devices are efficient in delivering the medication and can improve the clinical symptoms of asthma.

On the other hand, despite extant evidence, the administration of liquid aerosols or dry powder through pressurized dose-metered devices is still limited in Brazil, causing confusion, refusal and underuse among health professionals, patients and relatives.

Confusion and errors are verified when patients younger than five years are prescribed dry powder inhalers, when there is incorrect and/or inappropriate use of spacers, too

* PhD. Professor, Department of Pediatrics, Universidade Estadual de Campinas (UNICAMP), São Paulo, Brazil.

Suggested citation: Ribeiro JD. Aerosols and spacers for acute asthma in children. Evolution and time to change the routine. J Pediatr (Rio J). 2005;81:274-6. small or too large doses of bronchodilators, corticoids, mucolytics and antibiotics, misprescription of spacers, popular beliefs regarding the use of "asthma pumps," fear of side effects and use of spacers that are not scientifically approved, etc.

These problems occur due to the misinformation surrounding the evidence in favor of these devices, to the lack of information about the efficacy of inhalation in aerosol delivery, and also to the huge amount of available devices, making it difficult to choose among them.

The advantages and importance of aerosol administration include: lower doses, more rapid effects, fewer side effects, fewer systemic effects and action directed towards the target organ. Some drugs such as nedocromil, sodium cromoglycate, dornase alpha are only effective if inhaled, whereas inhaled beta-2 agonists substantially improve exercise-induced asthma, but this is not observed when these drugs are administered by other routes.

The use of spacers maximizes the release and minimizes the deposition of drugs in the oropharynx; therefore, pressurized metered-dose inhalers mustn't be used without spacers in children. ${ }^{9}$

The ideal inhaler should release a uniform amount of the drug, be appropriate for age, well accepted, easy to use, economically feasible and scientifically proven.

The National Asthma Education Program and Prevention ${ }^{10}$ recommendations are shown in Table 1.

Aerosols constitute a colloidal solution dispersed in a gas and in a liquid or solid phase. It is constituted by the suspensions of minute (liquid or solid) particles in a gas or mixed media of dispersion. Aerosols are produced by the following devices:

Pressurized inhalers: delivered in the form of jets and known as pressurized metered-dose inhalers (PMDI). The particles are liquid and released instantly. Before 1990, the PMDI used chlorofluorocarbon as propellants, which destroys the ozone layer. A new type of propellant, hydrofluoroalkane (HFA), has now been in use for 15 years. PMDI with HFA may be used in children and in elderly individuals, and without spacers (adults). However, the knowledge that the use of spacers doubles or triplicates aerosol doses, deposited in 
Table 1 - Recommendations of the National Asthma Education Program and Prevention ${ }^{10}$

\begin{tabular}{ll}
\hline Methods of aerosols administration & Age \\
\hline Small volume nebulizers & $\leq 2$ years \\
Pressurized metered-dose inhalers (PMDI) & $>5$ years \\
PMDI + spacers and mouthpiece & $>4$ years \\
PMDI + spacers and mask & $\leq 4$ years \\
Pressurized inhalers with endotracheal tube & Intensive Care Units (ICU) \\
Dry poweder inhalers & $\leq 5$ years \\
\hline
\end{tabular}

the airways, has encouraged the use of PMDI in all age groups. They are more frequently used at home and at hospitals because they are harder to carry along.

Dry-powder inhalers: (Rotahaler/Spinhaler, Turbuhaler, Diskhaler, Spiros, Accuhaler, Pulvinal, Diskus, etc). The first dry-powder aerosols appeared in 1971. The solid particles are released instantly. These models are easy to use because spacers are not required. They are indicated for children older than five years.

Nebulizers: they are jet air compressors that use oxygen or ultrasonic power. Oxygen nebulizers started to be used in the 19th century, and were the only type available until the mid-20th century. Ultrasonic nebulizers employ highfrequency sound waves and began to be used in 1960 .

Nebulizers are the oldest devices for aerosol administration and are still widely used. They release the drug in a liquid spray, gradually, for several minutes. Their use has been losing ground due to the fact that the amount of drug delivered to the airways cannot be properly determined. Ultrasonic nebulizers may impair the efficiency of the drugs. Oxygen nebulizers with bronchodilators and inhaled corticosteroids are still used in hospital for acute asthma attacks. The different devices for aerosol administration have advantages and disadvantages that should be made known and discussed with patients and their families. Choosing between one device and another depends on many factors and, regardless of the type of device used, some practical rules regarding aerosol administration include:

1) Use of household detergents as a practical and simple solution to the problem with electrostatic charge in plastic spacers, significantly improving the delivery of the aerosol to the lungs. ${ }^{11}$

2) These drugs should be ideally administered in the absence of crying. ${ }^{12}$

3) Spacers used in children are usually different from those used in adults.

4) Children under the age five years are unable to use PMDI without spacers or dry-powder inhalers.
5) The use of spacers with a mouthpiece is better than those with a face mask.

6) Education of patients and their families is essential to an adequate aerosol administration with different devices. Education also increases treatment compliance.

7) When prescribing an aerosol device, the physician should consider patient's age, family's preference, patient's ability to use it, costs, durability, commercial availability, formulation, dosing, type of drug to be used, place where it will be used (intensive care unity, nursery, emergency room or at home).

In the last 30 years, thousand of scientific articles have been published about the administration of aerosols for the treatment of obstructive pulmonary diseases. Several journals with a high impact factor have dedicated their editorials to these articles. Changes in the clinical management of respiratory diseases when treated with medications delivered through different aerosol devices have improved and decreased their morbidity and mortality, especially in the case of asthma.

In Brazil, the ingenuity, creativity and boldness of researchers from the states of Minas Gerais, ${ }^{13,14}$ Bahia, ${ }^{4}$ and Paraná 15 allowed for the development of new spacers, 13 comparison between different spacer sizes according to age, ${ }^{14}$ comparison of nebulizers with homemade spacers 4 and aerosol administration through different devices in acute asthma attacks with bronchial obstruction. ${ }^{15}$

All these articles aroused the interest in reading and applying the results obtained, and in giving suggestions, making criticisms and compliments. The results of these studies are the competence, responsibility and scientific rigor regarding the construction of simpler methods for aerosol administration in lung diseases. In the current issue of Jornal de Pediatria, we can read, with attention and interest, the study carried out by the Chong Neto et al., 15 which deals with a well-timed topic of great interest to pediatricians, pulmonologists, allergists/immunologists and clinicians. It is a useful article because asthma is the most 
common chronic childhood disease with a high prevalence, in which the use of medications is frequently brought into question. Since there is scant evidence about the use of dry-powder inhalers in acute asthma attacks, the study by Chong et al. fills an important gap in the literature and certainly motivates new studies in this area.

The use of aerosol devices in the management of acute asthma attacks must be evaluated by each medical unit. The technical and scientific improvement of aerosol devices shows that it is time to change the routine, since we buried myths over 30 years ago and now we have scientific evidence.

\section{References}

1. Mandelberg A, Tsehori S, Hour S, Gila E, Mora B, Prie IE. Is nebulized aerosol treatment necessary in the pediatric emergency department? comparison with a metal spacer device for metereddose inhaler. Chest. 2000;117:1309-13.

2. Closa RM, Ceballos JM, Gomez-Papi A, Galiana AS, Gutierrez C, Marti-Henneber C. Efficacy of bronchodilators administrated by nebulizer versus spacer devices in infants with wheezing. Pediatr Pulmonol. 1998;26:344-8.

3. Rubim JA, Simal CJ, Lasmar LM, Camargos PA. Deposição pulmonar de radioaerossol e desempenho clínico verificados com espaçador fabricado no Brasil. J Pediatr (Rio J). 2000;76: 434-42.

4. Vilarinho LC, Mendes CM, Souza LS. Inalador dosimetrado com espaçador artesanal versus nebulizador no tratamento da crise de sibilância na criança. J Pediatr (Rio J). 2003;79:403-12.
5. Amirav I, Newhouse MT. Metered-dose inhaler accessory devices in acute asthma: efficacy and comparison with nebulizers; a literature review. Arch Pediatr Adolesc Med. 1997;151:876-82.

6. Dolovich MB, Ahrens RC, Hess DR, Anderson P, Dhand R, Rau JL, et al. Device selection and outcomes of aerosol therapy: evidence based guidelines. American College of Chest Physicians/ American College of Asthma, Allergy, and Immunology. Chest. 2005; 127:335-71.

7. Castro-Rodriguez JA, Rodrigo GJ. Beta-agonists through metered-dose inhaler with valved holding chamber versus nebulizer for acute exacerbation of wheezing or asthma in children under 5 years of age: a systematic review with metaanalysis. J Pediatr. 2004;145:172-7.

8. De Benedictis FM, Selvaggi D. Use of inhaler devices in pediatric asthma. Pediatr Drugs. 2003;5:629-38.

9. Newman SP, Millar AB, Lennard-Jones TR, Moren F, Clarke SW. Improvement of pressurised aerosol deposition with nebuhaler spacer device. Thorax. 1984;39:935-41.

10. National Asthma Education and Prevention Program. Expert panel report 2: guidelines for the diagnosis and management of asthma. Bethesda, MD: National Heart, Lung, and Blood Institute, April 1997; NIH Publication No. 97-4051.

11. Wildhaber JH, Janssens HM, Pierart F, Dore ND, Devadason SG, LeSouef PN. High-percentage lung delivery in children from detergent-treated spacers. Pediatr Pulmonol. 2000;29:389-93.

12. Iles $R$, Lister $P$, Edmunds AT. Crying significantly reduces absorption of aerosolised drug in infants. Arch Dis Child. 1999;81:163-5.

13. Duarte M, Camargos PA. Efficacy and safety of a home-made non-valved spacer for bronchodilator therapy in acute asthma. Acta Paediatr. 2002;91:909-13.

14. Rocha Filho W, Noronha VX, Senna SN, Simal CJ, Mendonca WB. Evaluation of the influence of patient age and spacer device volume on aerosol lung deposition. J Pediatr (Rio J). 2004;80: 387-90.

15. Chong Neto HJ, Chong-Silva CD, Marani DM, Kuroda F, Olandosky M, Noronha L. Diferentes dispositivos inalatórios na crise aguda de asma: um estudo randomizado, duplo-cego controlado com placebo. J Pediatr (Rio J). 2005;81:298-304. 